13. Hailemariam B. Post menopausal vaginal bleeding due to vaginal wall leech infestation. Ethiop Med J. 1995;33:183185.

14. Shahraki AD, Aram S, Mohammadizadeh F. Leech infestation in the vulvar region: a possibility to be considered. Int J Prev Med. 2014;5:1630-1631.

\section{First Record of an Unusual Incident Between a Finfish-the White Snake Mackerel Thyrsitops lepidopoides (Teleostei, Gempylidae)—and a Surfer}

\section{To the Editor:}

On December 27, 2005, a 27-year-old man fell from his surfboard and hit his face on a solid object during a surfing session in the afternoon (4:00-5:00 PM) at Itararé Beach, in Sao Vicente, a city in the southeast coast of Brazil. He sustained a dislocated jaw and other facial injuries and presented to the nearest emergency department. Because he complained of a severe pain in his face, the emergency department suggested an initial diagnosis of sinusitis and recommended the use of antihistamines. After 3 days with continuous pain, he was taken to the ear, nose, and throat sector of Santa Casa da Misericordia Hospital, located in Santos, the nearest city, where a computed tomography scan detected fractures in the right maxillary sinus and inferior orbit. He underwent surgery, which began with an incision inside the mouth on the right side, at the height of the gingiva. After locating the first fracture, a foreign body was extracted. An endoscope was introduced in the area, and another foreign body near the orbit was found.

On January 6, 2006, our laboratory received 3 bottles from Santa Casa da Misericordia Hospital containing these foreign bodies in alcoholic solution. At first view, the bodies appeared similar to pieces of the jaw of a fish. A careful examination of the tooth pattern identified the pieces as the bottom jaw of a white snake mackerel, Thyrsitops lepidopoides (Cuvier, 1832) (Figure 1). This determination was based on the 8 to 10 small, uniserial, caniniform teeth interrupted by smaller molariform teeth (Figure 2) in each side of the jaw that were not turned back (as distinct from the barracuda genus Sphyraena).

The patient did not require hospitalization after removal of the fish jaw fragments. Abscesses were not reported in his wounds, and only minor edema was observed at the back of the right eye.

The white snake mackerel Thyrsitops lepidopoides is a species of teleost fish from the southwest Atlantic

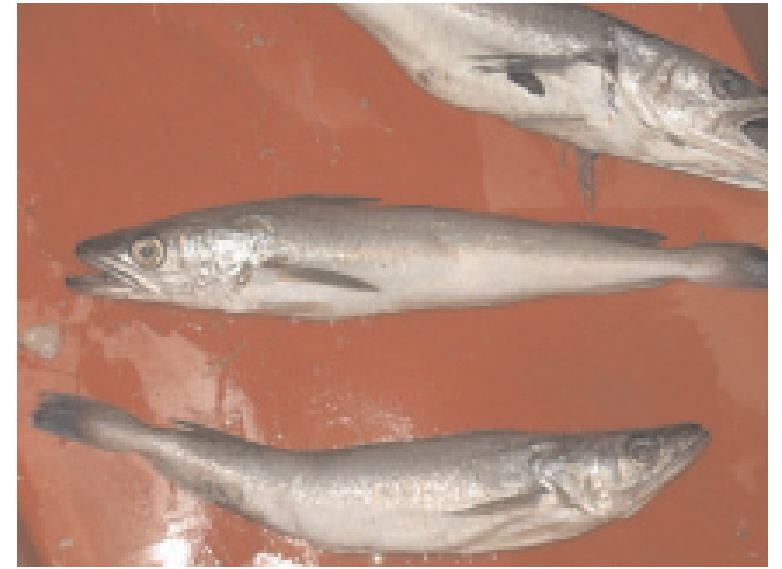

Figure 1. Fresh specimens of Thyrsitops lepidopoides (Cuvier, 1832) caught in the area near the accident (photography by the author).

common on both sides of South America that holds little interest for fishermen. During the austral summer months (December to February), this fish species often swims near the coast for feeding purposes (mainly on sardines and anchovies). ${ }^{1}$ Comparing the teeth found in the victim and the teeth of fresh white snake mackerel, we estimate that the fish was between 200 and $250 \mathrm{~mm}$ in total length.

The accident occurred on a popular urban shallowwater beach $\left(23^{\circ} 58^{\prime} \mathrm{S}\right.$ and $\left.46^{\circ} 21^{\prime} \mathrm{W}\right)$, located in the east of Santos Bay on the central coast of São Paulo State in southeastern Brazil. Previous reports show fish appearances in this area, which is a popular surfing location. The waves in this bay are mainly promoted by easterly winds that facilitate the invasion of colder waters on the coast. The discharge of urban sewage effluent into the sea through small channels results in an increase to the local eutrophication, promoting high availability of food for planktivorous species, such as sardine. As a consequence, predators such as the white snake mackerel flourish.

This is the first reported accident involving $T$ lepidopoides and humans. Except for sharks and rays, accidents involving surfers and other fish species are scientifically underreported. Most of the data refer to injuries caused by needlefish from the Belonidae family. ${ }^{2-4}$ Abnormal cases, such as bites attributed to the bluefish Pomatomus saltatrix, were reported in Florida. ${ }^{4}$ A review of emergency departments in Australia ${ }^{5}$ on cases of marine animal attacks did not indicate similar cases concerning other finfishes. 


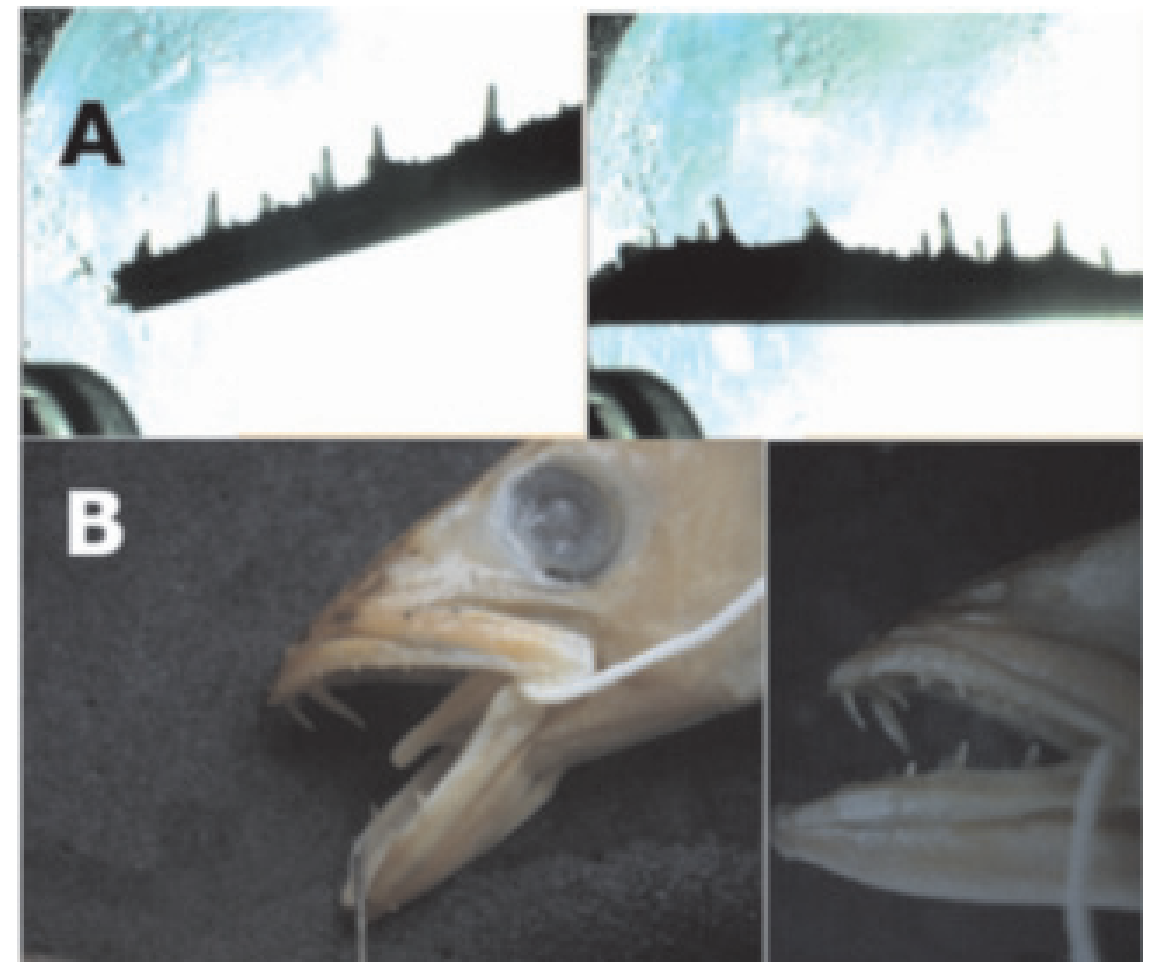

Figure 2. A, Pieces of the lower jaw removed from the nasal cavity of the victim (original magnification $\times 10$, with a stereomicroscope, photography by the author). B, Jaws of a preserved specimen from the fish collection of Rio de Janeiro State University (photography by H. R. S. Santos).

\section{Acknowledgments}

The author would like to thank Santa Casa da Misericordia Hospital and the patient who kindly and promptly reported the injuries. Marina M. Mattioli kindly revised the English version of this text. Hugo R. S. Santos (PhD, Curator of the Fish Collection of Universidade do Estado do Rio de Janeiro) provided photographs of a preserved specimen for comparison.

Acacio R. G. Tomas, PhD

Estuarine and Coastal Studies Laboratory, Marine Fisheries Center, The Fisheries Institute, Santos, SP, Brazil

\section{References}

1. Nakamura I, Parin NV. Snake mackerels and cutlassfishes of the world (families Gempylidae and Trichiuridae). An annotated and illustrated catalogue of the snake mackerels, snooks, escolars, gemfishes, sackfishes, domine, oilfish, cutlassfishes, scabbardfishes, hairtails, and frostfishes known to date. FAO Fisheries Synopsis. 1993;15:125.

2. Barss PG. Penetrating wounds caused by needle-fish in Oceania. Med J Aust. 1985;143(617-618):621-622.
3. de Sylva DP. Attacks by bluefish Pomatomus saltatrix on humans in South Florida. Copeia. 1976;1976:196-198.

4. Ebner Y, Golani D, Ophir D, Finkelstein Y. Penetrating injury of the maxilla by needlefish jaws. J Craniomaxillofac Surg. 2009;37:235-238.

5. Taylor DM, Ashby K, Winkel KD. An analysis of marine animal injuries presenting to emergency departments in Victoria, Australia. Wilderness Environ Med. 2002;13:106112.

\section{In Response to Snakebite Rebound Coagulopathy by Witham et al.}

To the Editor:

In the recent report of 2 cases by Witham et al, ${ }^{1}$ we question the identification of the snake for patient 2 , who was "believed to have been bitten on the foot by a copperhead snake" before being airlifted to Fort Worth, Texas, from an outlying hospital, likely to the west of Fort Worth. Fort Worth lies at the western edge of the natural range for copperheads (Agkistrodon contortrix) ${ }^{2}$ but well within the natural range for western diamondback rattlesnakes (Crotalus atrox). ${ }^{3}$ Witham et al provide no further evidence that this was a copperhead and not a rattlesnake. 